\title{
Warm Pressurant Gas Effects on the Static Bubble Point Pressure for Cryogenic LADs
}

\author{
Jason W. Hartwig ${ }^{1}$, John B. McQuillen ${ }^{2}$, David J. Chato ${ }^{3}$ \\ NASA Glenn Research Center, Cleveland, OH, 44135, USA
}

\begin{abstract}
This paper presents experimental results for the liquid hydrogen and nitrogen bubble point tests using warm press urant gas es conducted at the NAS A Glenn Res earch Center. The purpose of the test series was to determine the effect of elevating the temperature of the pressurant gas on the performance of a liquid acquisition device (LAD). Three fine mes $\mathrm{h}$ s creen samples $(325 \times 2300,450 \times 2750,510 \times 3600)$ were tes ted in liquid hydrogen and liquid nitrogen using cold and warm non-condens able (gaseous helium) and condensable (gas eous hydrogen or nitrogen) press urization schemes. Gases were conditioned from $0 \mathrm{~K}-$ $90 \mathrm{~K}$ above the liquid temperature. Results clearly indicate degradation in bubble point pressure using warm gas, with a greater reduction in performance using condens able over non-condensable pressurization. Degradation in the bubble point pressure is inversely proportional to screen porosity, as the coarsest mesh demonstrated the highest degradation. Results here have implication on both press urization and LAD sys tem design for all future cryogenic propulsion sys tems. A detailed review of his torical heated gas tests is als o presented for comparis on to current res ults.
\end{abstract}

\section{Nomenclature}

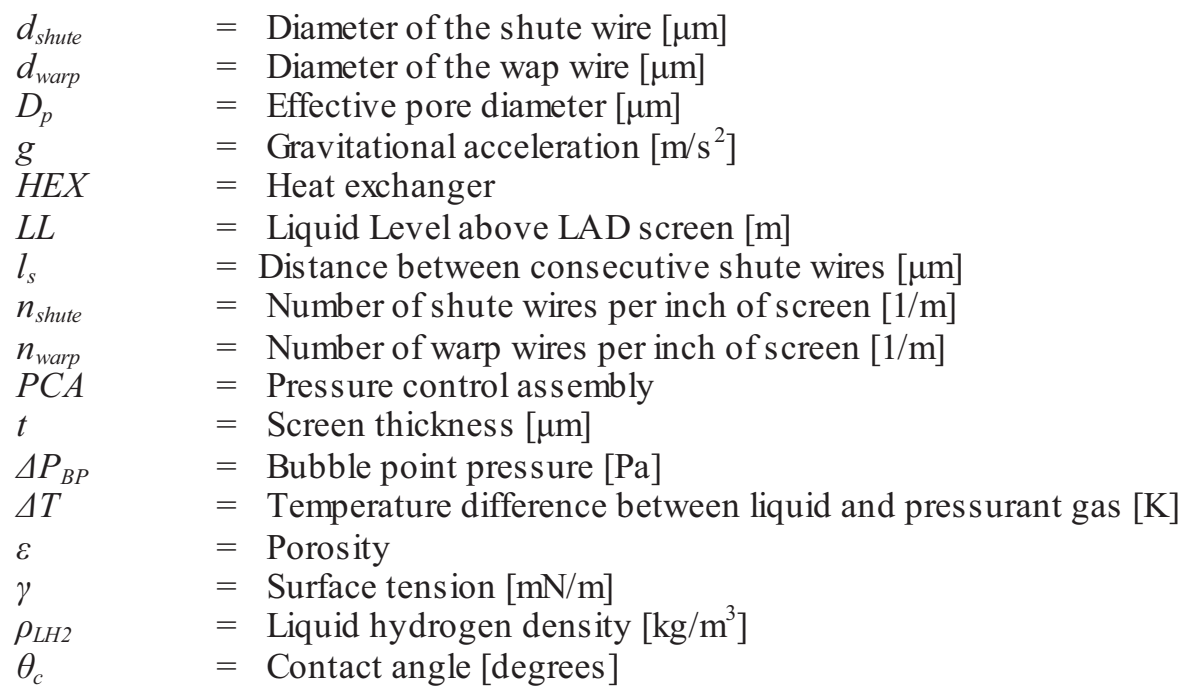

${ }^{1}$ Research Aerospace Engineer, Propellants and Propulsion Branch, 21000 Brookpark Road, MS 301-3, Cleveland $\mathrm{OH}, 44135$, Senior Member.

${ }^{2}$ Senior Aeros pace Engineer, Fluid Physics and Transport Branch, 21000 Brookpark Road, MS 77-5, Cleveland, OH 44135.

${ }^{3}$ Senior Aeros pace Engineer, Propellants and Propulsion Branch, 21000 Brookpark Road, MS 301-3, Cleveland, OH 44135, Associate Fellow. 


\section{Introduction}

$\mathrm{N}$ ASA maintains a strong desire to develop technology to enable long duration robotic and human space missions beyond Low Earth Orbit (LEO). Future des tinations include Earth-Moon Lagrange points, near-Earth objects (NEOs) such as asteroids, and eventually surface missions to the Moon, Mars, and beyond. The development of new and existing propulsion capabilities to send robot and human afar is necessary for the exploration and study of these locations of interest. Due to significant increase in propulsion system performance compared to storable propellants (fluids that exist as liquids at room temperature), the advancement of cryogenic fluid propulsion systems remains at the forefront of NASA's technology development program.

Liquid oxygen/liquid hydrogen $\left(\mathrm{LOX} / \mathrm{LH}_{2}\right)$ remains the top propellant combination owing to both an unmatched level of performance relative to other combinations, and due to proven flight heritage over the past 40 years in launch systems such as the Saturn V- S4, S4B, S2, Shuttle Space Transportation System(STS), short duration upper stages (J2). $\mathrm{LOX} / \mathrm{LH}_{2}$ systems also have potential usage for LEO fuel depots [1]. However there are challenging as pects when working with cryogenic propellants due to a low normal boiling point (NBP), low surface tension, and low viscosity. Cryogenic propellants are particularly susceptible to parasitic heat leak, which will make in-space storage and transfer a challenge.

\section{Screen Channel Liquid Acquisition Devices}

Technology development for $\mathrm{LOX} / \mathrm{LH}_{2}$ cryogenic propulsion systems begins upstream in the propellant tanks. Conceivably, there are two primary applications for in-space cryogenic liquid transfer, from the storage tank to the transfer line to an engine, or from a fuel depot to a customer s pacecraft receiver tank. All cryogenic propulsion engines require vapor free liquid to be delivered to the injectors. Receiver depot tanks will also require very high liquid fill fractions due to the projected cost of launching and storing propellant in LEO in fuel depots. Single phase liquid acquisition in Earth's 1-g environment is straightforward, since gravity drives the heavier liquid to the bottomand lighter vapor to the top of the propellant tank. In microgravity conditions of LEO however, any one of a number of special propellant management devices (PMDs) are required to draw sufficient liquid to the tank outlet in varying thermal and gravitational environments. One type of PMD, a screen channel liquid acquisition device (LAD), relies on capillary flow and surface tension forces to acquire and maintain communication between the bulk liquid and tank outlet at all times. As shown in Fig. 1, screen channel LADs follow the contours of the tank walls. The side that faces the wall is covered with a fine mesh screen that

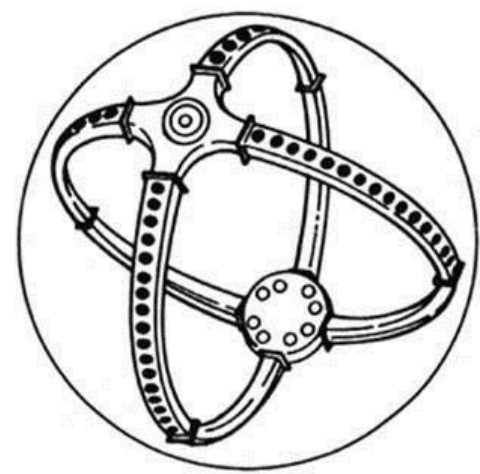

Fig. 1 Full Communication Screen Channel LAD wicks liquid into the channel and also blocks vapor ingestion during outflow if vapor is in contact with the screen.

Screen channel LADs are characterized by the screen weave and mesh type, which refers to the number of wires per inch of material and type of pattern used during manufacture. For example, the 510x3600 screen is a Dutch Twill mesh with 510 warp wires and 3600 shute wires per square inch (20079 warp and 141732 shute wires per meter) of material as shown in Fig. 2. Each shute wire passes under two warp wires before going over the next warp wire, which creates a tortuous path to vapor ingestion. The screen selection is dictated by specific mission requirements, which include gravitational and thermal environments, and flow rate demands. Finer mesh screens are favorable for $\mathrm{LH}_{2}$ systems to counter the low surface tension.

Screen channelLADs have proven flight heritage in storable propulsion systems such as the STS Reaction Control System(RCS) and Orbital Maneuvering System (OMS) [2 - 5], in cryogenic liquid helium(LHe) [6], but have not been used with $\mathrm{LH}_{2}$ or LOX in low gravity. For flight systems, screen channel LADs are divided into two regimes $[7,8]$. Start baskets or traps are small LADs that can be used in systems that experience large accelerations and large flow rates under short durations. Meanwhile full communication devices such as those

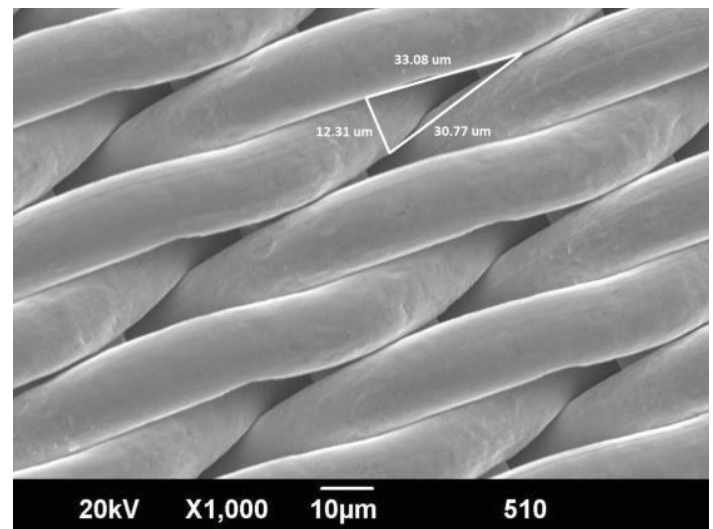

Fig. 2 Scanning Electron Microscopy Image of a $510 \times 3600$ Screen 
depicted in Fig. 1 are used in systems with small accelerations and small flow rates under longer durations.

\section{Pressurization System/LAD System Interaction}

During spaceflight, there are two primary sources of heat leak into the tank as indicated by the red arrows in Fig. 3; one as sociated with storage and one with transfer of the propellant. Radiation and conduction heat leak enters the tank through the support struts, fill, vent, and instrumentation penetrations. Mitigation strategies to reduce heat leak are straightforward; passive thermal control is used to reduce heat leak by using thick multi-layer insulation (MLI) blankets, composite struts, and optimizing the MLI layer density, while

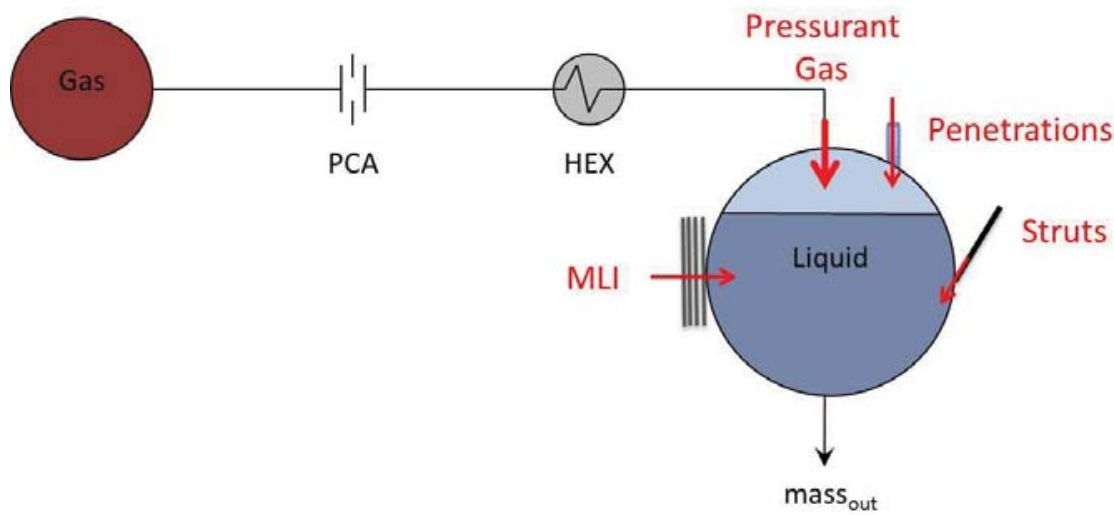

Fig. 3 Sources of Heat Leak into a Cryogenic Propellant Tank

active thermal control techniques use a cryocooler to reduce or eliminate propellant boil off. A second source of heat leak into the tank is fromwarm pressurant gas contacting the cold liquid propellant during liquid transfer. Mitigation strategies here are complicated. From a systems level standpoint, it is highly desirable to use warm gas as a pressurant because less mass is required to thermally condition the gas to tank conditions. From the LAD subsystem standpointhowever, it is desirable to use cold gas because LADs are surface tension driven devices, and colder temperatures result in better performance.

During spaceflight, the pressurant gas typically assumes the environmental temperature, which is warmer than the saturation temperature for cryogenic propellants at atmospheric pressure. Even if the pressurant tank bottle is thermally linked to the propellant tank, the pressurant gas temperature will most likely be warmer than the liquid temperature. As will be shown later, warm pressurant will always decrease the surface tension of the cryogen, cons equently, degrading the LAD performance. Clearly an optimal design point between the pressurization and LAD subsystems exists for each mission. In low gravity, warm gas may not impinge on the LAD screen until low tank fill levels, but tests are warranted to quantify the effect of heat absorption into the liquid on the LAD performance because warm gas will adversely affect the expulsion efficiency of the LAD.

In regard to the pressurization subsystem, there are two ways to pressurize a cryogenic propellant tank during liquid trans fer. Autogenous pressurization utilizes the liquid's own vapor such as gas eous hydrogen $\left(\mathrm{GH}_{2}\right) / \mathrm{LH}_{2}$ to pressurize while non-condensable pressurization employs a gas that will not condense into the liquid during pressurization. Froma systems level standpoint, autogenous pressurization is more attractive due to overall lower system mass and potential reduced system complexity. However, this system may require heaters or pressure building circuits to maintain sufficient liquid flow rates. In addition, autogenous pressurization complicates liquid transfer due to added heat and mass transport across the LAD screen during outflow, which can prematurely warm the liquid and potentially cause the LAD to break down early. Therefore autogenous pressurization may be insufficient to sustain high outflow rates for prolonged periods of time. Meanwhile, pressurization with a noncondensable gas, such as helium, results in less heat and mass transfer at the LAD screen during outflow and also incurs less dissolution [9] in all major cryogenic propellants. Heliumpres surization is likely sufficient to sustain all anticipated outflow rates [10]. However, non-condensable pressurization requires the use of onboard gas bottles as shown in Fig. 3, which increas es overall systemmass. In addition, GHe pres surization may be more expensive than autogenous pressurization because of the increasing cost of gaseous helium supplies. In a long duration depot mission GHe is a consumable resource which limits mission duration. Being able to generate pressurant (autogenous) eliminates issues associated with resupply of GHe. 


\section{The Bubble Point Pressure}

A screen channelLAD is said to have failed when vapor or gas is ingested into the channel, since the purpose of the LAD is to prevent gas ingestion into the channel. This failure or breakdown point is called the bubble point of the LAD screen. The bubble point is defined as the differential pressure across a LAD screen pore that overcomes the surface tension forces at that pore. Bubble point pressure is proportional to the surface tension of the liquid and inversely proportional to the effective screen pore diameter, as derived in Hartwig and Mann [11,12] and shown in Eq. 1:

$$
\Delta P_{B P}=\frac{4 \gamma \cos \theta_{C}}{D_{P}(T)}
$$

where $\gamma$ is the surface tension of the fluid, $\theta_{C}$ is the contact angle, and $D_{P}$ is the effective pore diameter. Vapor bubbles that penetrate into the channel may be condensed if conditions within the LAD are subcooled. However, helium bubbles that penetrate into the channel can only dis solve into the liquid, which is a very slow process, and could potentially cause engine instability.

The effective pore diameter is most readily determined through room temperature bubble point tests in a reference fluid such as is opropyl alcohol (IPA), which provides a good calibration range for low surface tension cryogenic liquids. Hartwig et al. [13] showed that the effective pore diameter is temperature dependent, and derived a simple pore diameter model to account for screen pore diameter shrinkage at colder temperatures to account for differences in bubble points for the same screen that could not be attributed to the fluid surface tension. Measurement of pore diameters using scanning electron microscopy (SEM) imaging has proven unreliable [14, 15]. In addition, there are inconsistencies about performance based on wire counts. For example, the 450x2750 mesh outperforms both the $325 \times 2300$ and $510 \times 3600$ meshes in room temperature and cryogenic liquids [14, 16]. However, the performance of the coarser 325 mesh surpasses the performance of the 510 mesh in room temperature liquids, but the opposite occurs in liquid nitrogen $\left(\mathrm{LN}_{2}\right)$ and $\mathrm{LH}_{2}$. Note that Eq. 1 does not differentiate for pressurization gases. Previous experimental programs using cryogenic liquids, $\mathrm{LH}_{2}, \mathrm{LOX}$, and liquid methane $\left(\mathrm{LCH}_{4}\right)$ have demonstrated better performance when pressurizing with a non-condens able pressurant gas like GHe versus pressurization with a condensable gas such as $\mathrm{GH}_{2}[14,17-19,20]$.

Screen channel LADS have flight heritage with storable propellants where heat transfer effects are not as severe as they are for cryogenic propellants. Before these LADs can be routinely used in cryogenic propulsion systems, the effects of undesirable heat on the LAD must be fully quantified. This environmental parasitic heat leak into the tank or heat input fromwarm pressurant gas may adversely affect LAD performance by vaporizing the liquid and drying out of the LAD screen. The static bubble point pressure is the upper limit on the total allowable pressure loss in a LAD systemand therefore serves as the primary performance parameter for characterizing a screen channel LAD.

\section{Test Objectives}

Is sues that arise in $\mathrm{LH}_{2}$ cryogenic fluid management have been addressed through a battery of ground tests between FY11 - FY13 as part of the Cryogenic Propellant Storage and Transfer (CPST) technology maturation. Previous work has addressed the effect of varying the screen mesh, liquid, liquid temperature and pressure, and type of pressurization gas on the liquid hydrogen bubble point [13]. The purpose of this work was to examine the effect of warm pressurant gas on the bubble point of screen channel LADs. The goal is to give mission designers direct insight into the combined LAD and pressurization subsystemperformance and design for future cryogenic engines and cryogenic fuel depots.

\section{Experimental Design}

Testing was performed at the Cryogenic Components Lab 7 (CCL-7) at Glenn Research Center(GRC) in Cleveland, Ohio. Pore sizes for 325x2300 (12795 warp and 90551 shute wires per meter), 450x2750 (17716 warp and 108268 shute wires per m), and 510x3600 (20079 warp and 141732 shute wires per meter) Dutch Twill were determined in room temperature tests $[11,12]$. The exact same samples were used here for heated pressurant gas tests in cryogenic liquids. LAD screen samples, $6.5 \mathrm{~cm}(2.5 \mathrm{in})$ in diameter, were cut and welded to a heavy flange to create a tight sealalong the edges as shown in Fig. 4. Each screen was mounted to its own flange to permit rapid change out. The screen was mated with a cylindrical cup shown in Fig. 5. The purpose of the cup was to create the liquid/vapor interface $(\mathrm{L} / \mathrm{V})$ within the screen pores by pressurizing frombeneath the screen for the inverted bubble point (IBP) test configuration. The cup was equipped with a central support rod as shown in Fig. 6. The rod had a custom fabricated cross to allow for slow, uniform pressurant gas injection into the cup. The rod also supported three annular thin film Kapton heaters which warmed the incoming pressurant gas to the desired temperature before 


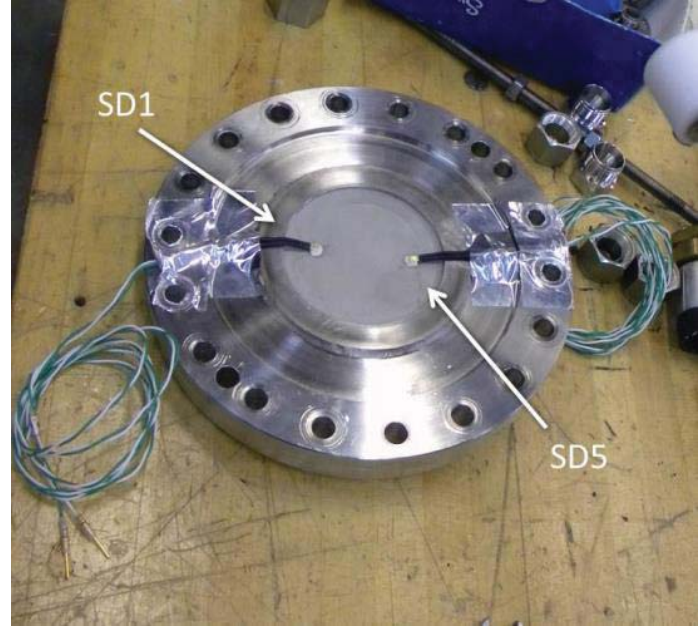

Fig. 4 LAD Screen Sample and Flange

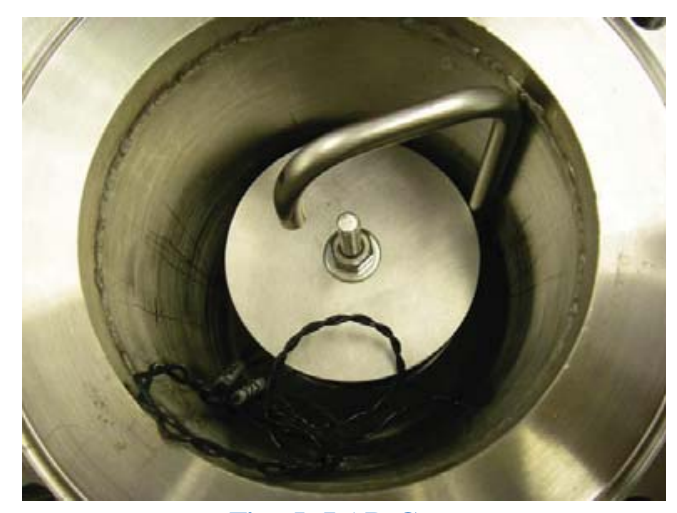

Fig. 5 LAD Cup

incidence on the LAD screen. A heater was placed on the underside of the bottom and top disc, and the top of the bottom disc, which eliminated view factors between heating source and LAD screen, and ensured that all of the heating was via conduction and convection of the incoming pressurant gas. This design forced uniform heating and pressure rise within the cup. It also eliminated direct warm gas impingement on the screen. Bubble point pressure was deduced from the raw differential pres sure transducer (DPT) measurement from the sense line shown in Fig. 5. The sensing port pointed away from the screen to eliminate flooding of the line and to eliminate two phase DPT signals. The complete as sembled LAD screen and cup is shown in Fig. 7.

The LAD screen and cup assembly was placed in a dewar. The purpose of the dewar was to house the liquid cryogen on top of the LAD screen. A polished aluminum plate was mounted above the screen and cup assembly and reflected an image of the LAD screen through a viewport on the side of the dewar to a camera. A fiber optic light source illuminated the screen. A camera was attached to the side viewport to monitor the test in real time. Time synchronization between camera and data was maintained through a custom time synchronization system. Facility air ejectors were used to control pressure and thus temperature of the liquid. The facility was modified to use $\mathrm{GHe}$ and $\mathrm{GH}_{2}$ as pressurants for $\mathrm{LH}_{2}$ testing and $\mathrm{GHe}$ and gas eous nitrogen $\left(\mathrm{GN}_{2}\right)$ as pressurants for $\mathrm{LN}_{2}$ tests.

Pressure in the dewar was controlled by a proportionalintegral-derivative (PID) loop. Liquid temperature was controlled by conditioning the liquid in storage dewars that were connected to the facility. Liquid temperature would gradually increase due to parasitic heat leak into the dewar and through introduction of the warmpressurant gas. The liquid was evaporatively cooled by reducing pressure within the dewar. Temperature of the pressurant gas was monitored using a silicon diode inside the LAD cup and controlled by cycling on or off the heaters, which were controlled through a tight PID loop using a silicon diode inside the LAD cup.

All temperatures were measured using silicon diodes as point sensors. Critical measurements for heated pressurant gas tests were the temperature of the liquid and gas side of the LAD screen, temperature of the pressurant gas, pressure of the ullage, DPT across the LAD screen, and pressurant gas mass flow rates into the cup. All data was recorded at $5 \mathrm{~Hz}$ with a computer data acquisition system (DAQ). Videos of the LAD screens were time stamped and recorded to compare with the time stamp in the data. All diodes measured temperature to within 0.1 $\mathrm{K}$. Ullage pressure was measured to within $2.3 \mathrm{kPa}$ accuracy. The raw DPT reading was accurate to within $0.324 \mathrm{~Pa}$, but due to signal interpretation and processing, video read off errors, interpolation between recorded values, the total uncertainty in the corrected bubble point pressure is estimated to be $12 \mathrm{~Pa}$, which is $10 \%$ uncertainty in the lowest reported bubble point pressure for the heated gas runs. This low absolute error in measurement relative to previously reported cold gas tests was made possible by modifications in the DAQ system.

Experimental methodology and the original test matrix are outlined in previous work [16]. To conduct a heated pressurant gas bubble point test, a GHe flow was first established across the

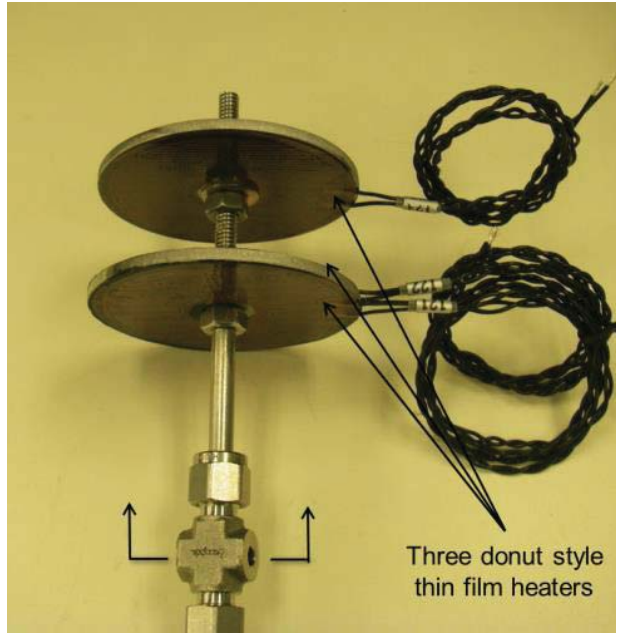

Fig. 6 Heater Bank 
screen during liquid fill of the dewar to prevent flooding of the cup. Heated pressurant gas testing was always conducted in above atmospheric pressure conditions, which eliminated the need to pre-condition the liquid. The liquid temperature only varied between a small range of $20.5 \mathrm{~K}-21.0$ $\mathrm{K}$, which allowed independent examination of the effect of heated pressurant gas on LAD performance. When the dewar was filled to the desired liquid level, the pressurant gas type was selected and allowed to flow through the flow network for a period of 10 minutes or more. The screen was then allowed to reseal. The heaters were then engaged until the desired temperature of the pressurant gas was achieved. The gas was always allowed several minutes residence time to come to equilibrium at the desired gas temperature before attempting a controlled breakthrough . Then the pressure underneath the LAD screen was slowly increased untila bubble broke through the wetted screen as indicated on the live video and in the sharp rise in the DPT signal. The screen was then resealed. Bubble points were repeated at similar pressurant gas temperatures for repeatability before moving on to the next gas temperature. Due to the low surface tension of $\mathrm{LH}_{2}$ and low baseline cold gas bubble point values, it was sometimes difficult during testing to even reseal the screens. Raw bubble point pressures were corrected for liquid head pressure:

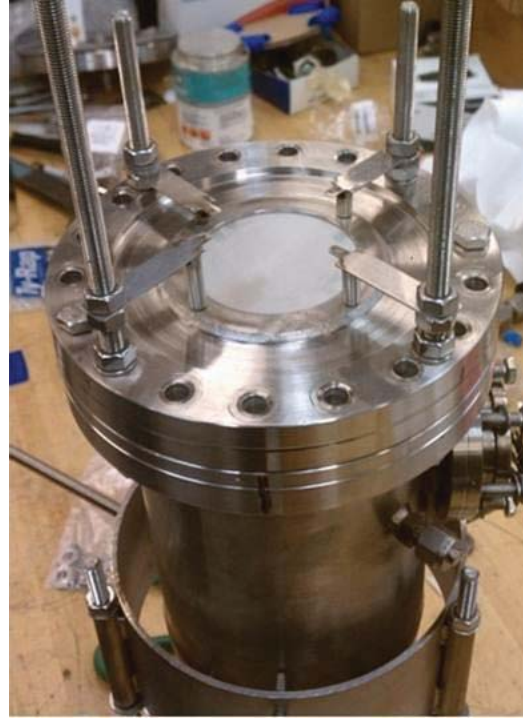

Fig. 7 Completed LAD Screen/Cup Assembly

$$
\left.\Delta P_{B P}(T, P)\right|_{\exp }=D P T-\rho_{L H 2} g L L
$$

where $L L$ was the liquid level above the screen in the dewar as determined by a vertical silicon diode rake.

The test matrix consisted of the following: Three fine mesh screen channel LAD samples $(325 \times 2300,450 \times 2750$, and 510x3600) were tested in two cryogenic liquids $\left(\mathrm{LH}_{2}\right.$ and $\left.\mathrm{LN}_{2}\right)$, with two pressurization schemes (condensable $\mathrm{GH}_{2} / \mathrm{LH}_{2}$ and $\mathrm{GN}_{2} / \mathrm{LN}_{2}$ and non-condensable $\mathrm{GHe} / \mathrm{LH}_{2}$ and $\mathrm{GHe} / \mathrm{LN}_{2}$ ) at several different pressurant gas temperatures. Bubble point data was first collected using cold pressurant gases. The cold baseline temperature of $20.3 \mathrm{~K}$ was approximately equal to the liquid temperature to minimize the temperature gradient across the screen at breakdown. This was only possible because the LAD cup was immersed in the liquid. To collect data at elevated temperatures, the heaters were engaged to several different fixed gas temperatures and measurements repeated to allow comparis on with the cold gas data using Eq. 2.

\section{Liquid Hydrogen Tests}

Using the current hardware and test configuration, parametric testing was conducted to independently examine the effect of six different parameters on the bubble point pressure. The parameters included screen weave, liquid (surface tension), liquid temperature and pressure, pressurization gas type, and pressurization gas temperature. Results fromtesting with cold gas [13] are used to establish the baseline reference bubble point values. Bubble point is directly proportional to the surface tension of the liquid in Eq. 1. The pressure dependence on bubble point is believed to be a modification of the temperature dependence [19, 20]. Higher pressures relative to the saturation pressure, and thus higher levels of liquid subcooling at the screen, produced higher bubble points for previously reported $\mathrm{LOX}$ and $\mathrm{LCH}_{4}$ data.

Figure 8 establis hes the effect of changing the screen weave, liquid temperature and pressure, and pressurization gas type on the $\mathrm{LH}_{2}$ bubble point pressure by plotting data for all three screen meshes and both pressurant gases. The trends are as follows: First, for all three meshes, and for both pressurant gases, bubble point decreases with increas ing liquid temperature, due to decreas ing surface tension. The highest bubble point pressures are always obtained in the coldest liquid temperatures, regardless of screen or gas type. Second, for all three meshes, regardless of liquid temperature, bubble points obtained using the non-condensable gas are always higher than those obtained using the condensable gas. Gaseous helium adds margin to the bubble point pressure while $\mathrm{GH}_{2}$ acts like a degradation factor. The dis parity between pressurization schemes is relatively fixed for all three LAD screen meshes tested here. Third, for all liquid temperatures and for both pressurant gases, bubble point pressure does not scale with the mesh of the screen. This is the most complextrend of the original five parameters tested [14]. The second

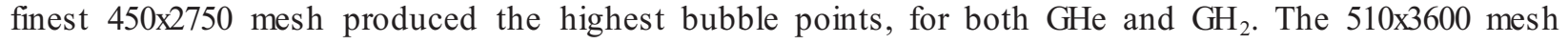
outperformed the $325 \times 2300$ mesh at $\mathrm{LH}_{2}$ temperatures, but the $325 \times 2300$ yielded higher pressures in room temperature liquids $[11,12]$. The reas on for this crossover in performance is due to the temperature dependence of the screen pore diameter, as mentioned previously. In addition, the contro lling parameter for gain in performance 
with reduced temperature is the shute to warp diameter ratio [21]. The geometry of the $\mathrm{L} / \mathrm{V}$ interface at breakthrough is dependent on this ratio, and as previously shown, the 510 screen has the largest gain at $\mathrm{LH}_{2}$ temperatures.

The sixth and final parameter that was investigated was the temperature of the pressurantgas. Data is first presented on an abs olute scale to allow direct comparison to cold gas data. Figure 9 plots all $\mathrm{LH}_{2}$ bubble point data collected using warm pres surant gas. Data is plotted as a function of the temperature difference between warm gas and cold liquid at breakthrough. Controlled breakthroughs and reseals were achieved for gas temperatures between $30 \mathrm{~K}<\mathrm{T}_{\mathrm{GAS}}<$ $116 \mathrm{~K}$ which correspond to a temperature difference across the screen of $10 \mathrm{~K}<\Delta \mathrm{T}<$ $95 \mathrm{~K}$. As shown for all three screens, the bubble point pressure decreases linearly with increasing pressurantgas temperature. The degradation in bubble point is more pronounced using $\mathrm{GH}_{2}$ vs. pressurizing with $\mathrm{GHe}$ as the $325 \times 2300$ and $450 \times 2750$ screens failed to reseal at temperature differences of $34 \mathrm{~K}$ and $69 \mathrm{~K}$, respectively using the condensable gas. Meanwhile, controlled breakthroughs were achieved with all three meshes using GHe beyond temperature differences of $50 \mathrm{~K}$. Regardless of the pressurization method, the onset of degradation is immediate for gas temperatures greater than the liquid temperature. This is in contrast to previously reported $\mathrm{LH}_{2}$ heated gas bubble point pressures where the onset of degradation would occur at a certain gas temperature.

To allow comparis on between the four different LAD test methods in Appendix A, a normalized bubble point ratio is defined:

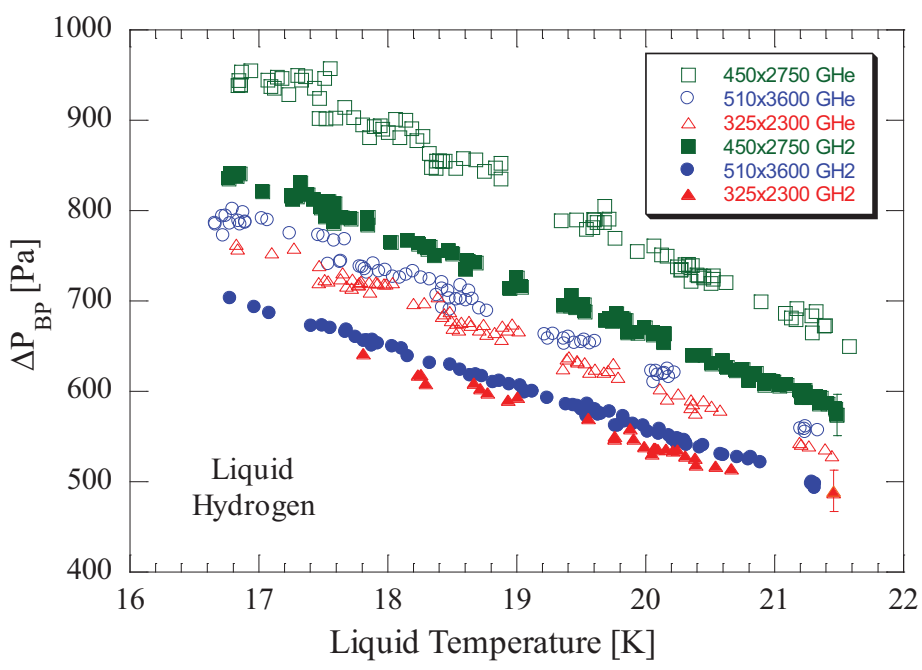

Fig. 8 Cold Gas Liquid Hydrogen Bubble Point as a Function of Liquid Screen Side Temperature.

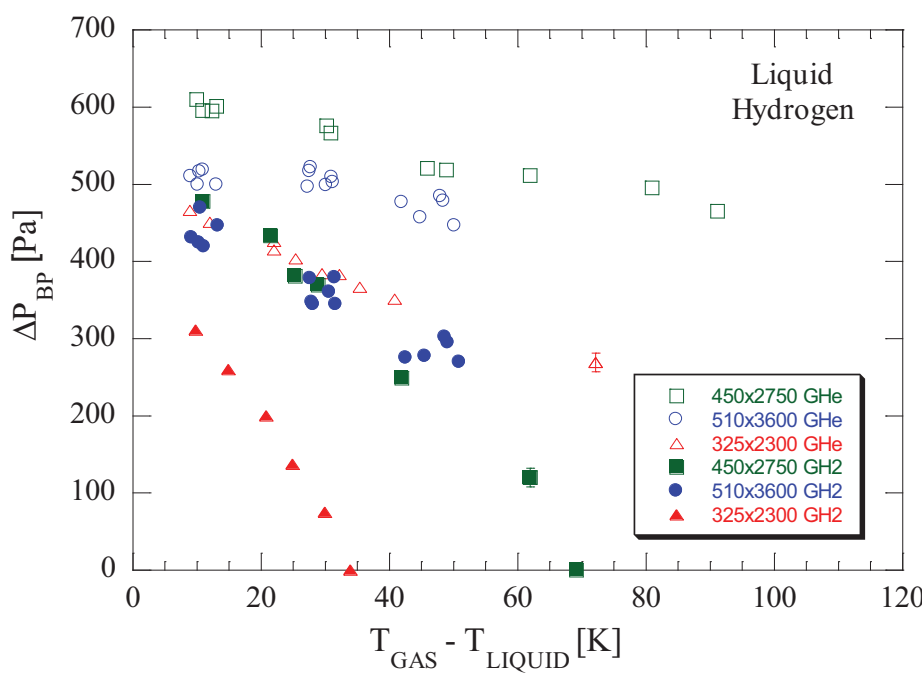

Fig. 9 Heated Pressurant Gas $\mathrm{LH}_{2}$ Bubble Point as a Function of Temperature Difference between Pressurant Gas and Liquid.

$$
\frac{\Delta P_{B P}(\Delta T)}{\Delta P_{B P}(\Delta T=0)}
$$

where $\Delta T$ is the temperature difference between liquid propellant and pressurization gas. Therefore the denominator is the normal breakdown value for equal gas and liquid temperatures, and the numerator is the breakdown value when the gas is sufficiently heated above the liquid temperature (i.e. the temperature difference across the screen). The normalized ratio is plotted as a function of the temperature difference across the screen.

Figure 10 plots heated bubble point pressures using Eq. 3 to normalize the data to the cold gas value obtained at the liquid temperature. Since each controlled breakthrough/reseal pair occurred at different liquid temperatures spaced over an approximate temperature range of $21 \mathrm{~K}<\mathrm{T}<22 \mathrm{~K}$, each point was normalized to its own cold gas bubble point pressure, as opposed to a single value. Therefore, at a temperature difference across the screen of $0 \mathrm{~K}$, there is no deviation from the unheated pressurant gas bubble point ratio, by definition. Data is again plotted as a function of the $\Delta \mathrm{T}$ across the screen. Lines are simple linear fits to the data. 
Normalizing the data shows three distinct trends. First, for all 3 screens and both pressurant gases, heating the gas above the liquid temperature acts as a degradation factor on the cold gas bubble point pressure. The larger the temperature difference across the screen, the earlier the screen will break down. Second, for all three screens, bubble point pressure degrades from the cold gas value much more rapidly using condensable gas than using non-condensable gas as indicated by steeper slopes in the linear curve fits. Third, for both pressurization schemes, degradation in bubble point is inversely proportional to the porosity of the screen. Porosity is the ratio of open area for fluid to flow through the screen divided by the total screen area. Porosity for the LAD screens is defined as:

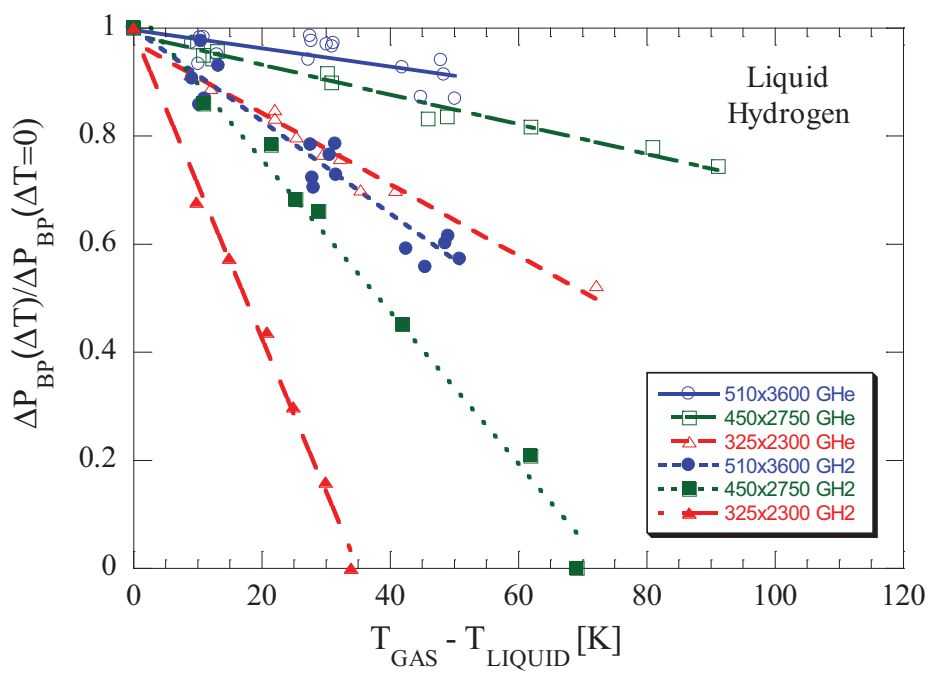

Fig. 10 Normalized Heated Pressurant Gas $\mathrm{LH}_{2}$ Bubble Point Pressure as a Function of the Temperature Difference between Pressurant Gas and Liquid at the LAD Screen.

$$
\varepsilon=1-\frac{\pi}{4}\left(n_{w} d_{w}^{2}+0.5 n_{s} d_{s}^{2}+0.5 n_{w} n_{s} d_{s}^{2} l_{s}\right)
$$

where $n_{w}$ and $n_{s}$ are the number of warp and shute wires per inch of screen material, respectively, $d_{w}$ and $d_{s}$ are the diameters of the warp and shute wires, and $l_{s}$ is the distance between consecutive shute wires as defined by [22]:

$$
l_{s}=\sqrt{\left(d_{w}+d_{s}\right)^{2}+\left(\frac{1}{n_{w}}\right)^{2}}
$$

Computed screen thicknesses and porosities are shown in Table 1. Therefore higher porosities indicate more open area for the gas to interact directly with the liquid. As shown in Fig. 10, the finest 510x3600 mesh exhibited the smallest degradation in performance over the $450 \times 2750$ and $325 \times 2300$ screen, as indicated by the slopes of the linear curve fits. This trend holds for both pressurization schemes. As is evident in Figs. 9 and 10, although the $450 \times 2750$ screen outperforms the $510 \times 3600$ on an absolute basis, degradation in performance for the $510 \times 3600$ screen is less.

\begin{tabular}{|c|c|c|c|}
\hline Screen & Screen Thickness [ $\boldsymbol{\mu m}]$ & Is $[\boldsymbol{\mu m}]$ & $\boldsymbol{\varepsilon}$ \\
\hline $325 \times 2300$ & 88.9 & 100.7 & 0.245 \\
\hline $450 \times 2750$ & 66 & 72.8 & 0.267 \\
\hline $510 \times 3600$ & 56.4 & 65.0 & 0.284 \\
\hline \multicolumn{3}{|r|}{ Table 1 - Calculated Screen Parameters } \\
\hline
\end{tabular}

Coarser screens are likely to sustain higher temperature differences across the screen prior to bubble breakthrough, causing the local interfacial temperature to increase significantly higher than finer meshes. For Dutch Twill screens, the screen thickness for a heated gas bubble to traverse from gas to liquid side of the screen is approximately equal to:

$$
t=\left(2 * d_{\text {shute }}\right)+d_{\text {warp }}
$$

Therefore coarser Dutch Twills are thicker and have lower porosities relative to finer Dutch Twills. These longer path lengths for warmgas or vapor to travel through the screen coupled with less overall open area for gas and liquid 
to exchange heat and mas s causes larger temperature differences to build across the screen before the actual visible warm gas bubble breaks through the screen. The finest 510 mesh is the thinnest screen and has the smallest pores, and largest porosity, making it easier for heat and mass to transport across the screen between liquid and gas prior to breakdown. Since mass is more easily transferrable across the screen, the local gas at the screen pore will cool slightly, cooling the interface temperature relative to the coarser meshes long before the bubble breaks through the screen. Meanwhile, for the coarser mesh, the larger pore size, thicker screen, and lower porosity causes larger temperature differences across the screen to build prior to breakdown. The larger pore sizes and less contact area between warm gas and cold liquid prevent heat transfer from the gas into the liquid.

Data shows that coarser screens like 200x1400 and 325x2300 have larger temperature differences across the screen at breakdown [23]. The dominate mode of heat trans fer for the finer mesh screens is primarily parallel path heat conduction: conduction within the metal and conduction within the liquid phase trapped initially in the mesh. Except at breakthrough, there is little convective motion through the screen as the tiny pore size and the liquid viscosity limit the motion.

The degradation in performance using condensable gas can also be explained as follows: As warm condensable vapor passes through the screen, it condenses into the liquid, and warms the L/V interface, reducing the surface tension and thus bubble point. For GHe pressurization, the small additional margin in bubble point pressure is due to the suppression of the local partial pres sure of $\mathrm{GH}_{2}$ within the screen pores. Free mass transport is minimized with helium present, butheat conduction between warmgas and cold liquid still occurs at a slightly lower rate relative to $\mathrm{GH}_{2}$ pressurization. Messerole and Jones [24] speculated that for $\mathrm{GH}_{2}$ pressurizaion, the liquid may be in a locally superheated state at the screen, which may cause any heat input in to the liquid to produce bubbles immediately and lead to the liquid detaching from the screen. Meanwhile, for GHe pressurization, the liquid at the screen may be in a slightly subcooled state, since GHe has been shown to evaporate liquid away from the screen [19,20].

Results are in fair agreement with Cady's [25] previously reported non-inverted bubble point(NIBP) results using a 325×2300 mesh and GHe; he showed a smaller degradation factor (despite higher heat transfer rates) of only 10\% at a gas temperature 55K above the liquid temperature. However, Cady also reported near identical degradation in performance for several different meshes, which is in disagreement with the current study. The currentstudy is also in agreement with Burge and Blackmon's [7] heated $\mathrm{GH}_{2}$ NIBP data for a 250x1370 that showed steeper degradation relative to the $325 \times 2300 \mathrm{GH}_{2}$ here. Note that the $250 \times 1370$ screen has a lower porosity relative to the $325 \times 2300$ and would be expected to degrade more relative to the finer meshes.

\section{Liquid Nitrogen Tests}

Heated pressurant gas tests were also conducted in $\mathrm{LN}_{2}$ using the same exact screens, experimental design, and procedure. Only the DPT that was used to measure raw bubble point pressure was changed to a higher range DPT to account for the higher $\mathrm{LN}_{2}$ surface tension, and thus bubble point, relative to $\mathrm{LH}_{2}$. Results are plotted in Figs. 11 - 13. First, the cold pressurant gas bubble point pressure as a function of the liquid screen side temperature is plotted to establish the baseline reference value. The same trends visible in $\mathrm{LH}_{2}$ data are reflected in the $\mathrm{LN}_{2}$ data in Fig. 11. For all three meshes and both pressurant gases, $\mathrm{LN}_{2}$ bubble point pressure decreases with increasing liquid temperature. For all temperatures and meshes tested, pressurization with thenoncondensable GHe yields higher performance over pressurization with the condensable $\mathrm{GN}_{2}$. For both pressurant gas es and all liquid temperatures tested, the same trend between screen meshes is evident with $\mathrm{LN}_{2}$ as in $\mathrm{LH}_{2}$ tests. The second finest $450 \times 2750$ yields the highest bubble points, followed by the finest $510 \times 3600$ screen, followed by the coarsest

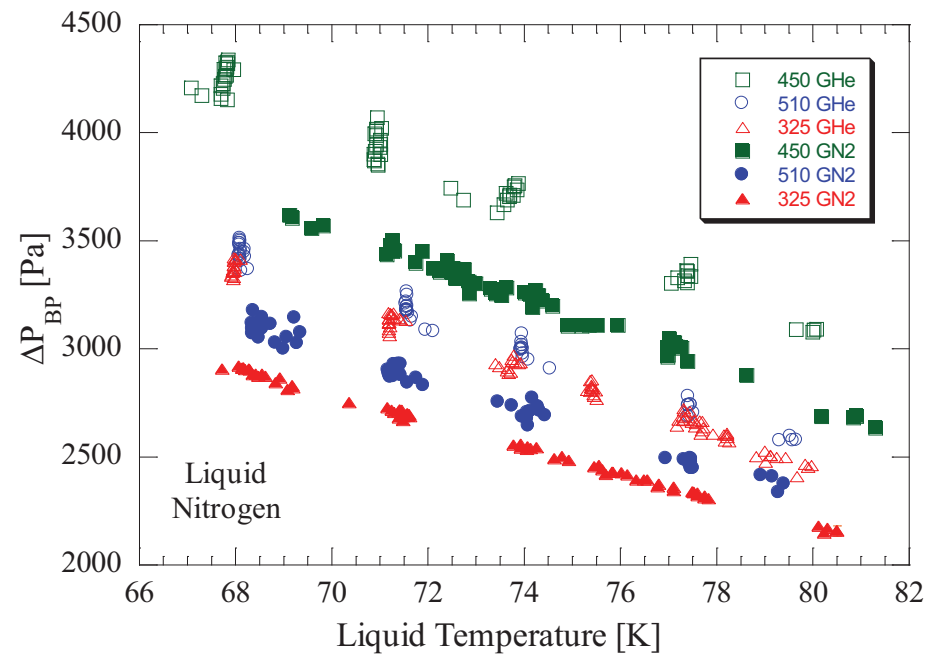

Fig. 11 Cold Gas Liquid Nitrogen Bubble Point as a Function of Liquid Screen Side Temperature. All data was taken at a pressurant gas temperature approximately equal to the liquid temperature. $325 \times 2300$ mesh. 
Figure 12 plots heated pressurant gas bubble point data, on an absolute scale, as a function of the temperature difference across the screen at breakthrough. The liquid temperature for all of these tests was between the range of $79 \mathrm{~K}<\mathrm{T}_{\text {liquid }}<$ $81 \mathrm{~K}$. Controlled breakthroughs were achieved for gas temperatures between $80 \mathrm{~K}<\mathrm{T}_{\mathrm{GAS}}<211 \mathrm{~K}$ which corres pond to a temperature difference across the screen of $1 \mathrm{~K}<\Delta \mathrm{T}<131 \mathrm{~K}$. Higher gas temperatures using $\mathrm{GHe}$ and $\mathrm{GN}_{2}$ in $\mathrm{LN}_{2}$ were achieved due to greater temperature stability of the $\mathrm{LN}_{2}$ during testing; more controlled breakthroughs and reseals were achievable due to the higher $\mathrm{LN}_{2}$ surface tension. As shown for all three screens, bubble point pressure decreases with increasing pressurant gas temperature. The degradation is again more pronounced using the condensable gas versus the GHe case. However, examination of Fig. 12 shows that the slopes in degradation for $\mathrm{LN}_{2}$ are not as sharp as those for $\mathrm{LH}_{2}$. In addition, for the $450 \times 2750$ and $510 \times 3600$ screens using GHe pressurization, the onset of degradation does not occur immediately.

To elucidate this apparent trend, Fig. 13 plots heated bubble point pressures using Eq. 3 to normalize the data to each cold gas bubble point value. Data is plotted as a function of the $\Delta \mathrm{T}$ across the screen. Lines are fits to the data from the onset of degradation. The same trends in previous $\mathrm{LH}_{2}$ data are reflected here in $\mathrm{LN}_{2}$. Warmer press urant gas temperatures degrade the bubble point ratio. Bubble point pressures degrade quicker using $\mathrm{GN}_{2}$ over $\mathrm{GHe}$ pres surization as indicated by the steeper rate slopes. Degradation in bubble point is again inversely proportional to the porosity of the screen for both pressurization schemes. However, unlike $\mathrm{LH}_{2}$ results, where the onset of degradation occurred immediately, onset of degradation in performance for the 450x2750 using GHe and $510 \times 3600$ using both $\mathrm{GHe}$ and $\mathrm{GN}_{2}$ does not occur until a minimum temperature difference is achieved $(41 \mathrm{~K}, 77 \mathrm{~K}$, $21 \mathrm{~K}$, respectively). Compared to historical NIBP results from Castle [26], no degradation in performance was noticed for any of the fine Dutch Twill screens, including the 200x1400, 325x2300, or 450x2750 screens over a much larger temperature range using $\mathrm{GN}_{2}$ pressurant.

$\mathrm{LN}_{2}$ bubble points degrade less than $\mathrm{LH}_{2}$ over the same range of $\Delta \mathrm{T}$. This could be due to the fact that $\mathrm{LN}_{2}$ has a higher surface tension and higher heat capacity relative to $\mathrm{LH}_{2}$, making it harder to alter the effective interfacial temperature and thus surface tension of the liquid at the screen pore. Castle [26] claimed that differences in degradation between $\mathrm{LH}_{2}$ and $\mathrm{LN}_{2}$ are because $\mathrm{LH}_{2}$ is more susceptible to drying outbecause of the lower superheat required to initiate boiling. Differences could als o be due to a stronger change in surface tension with temperature for hydrogen over nitrogen.

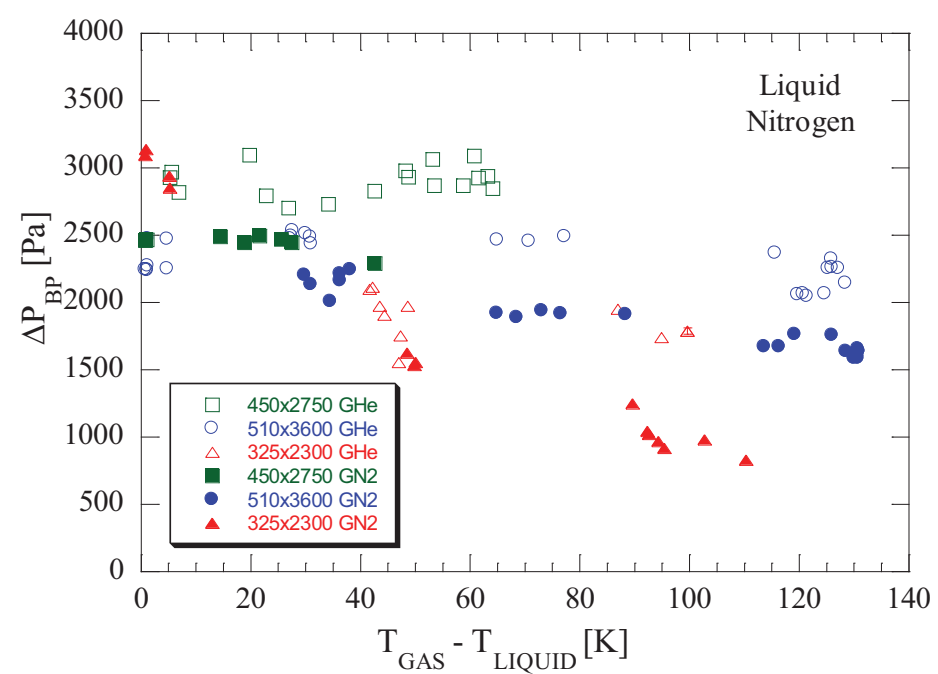

Fig. 12 Heated Pressurant Gas $\mathrm{LN}_{2}$ Bubble Point as a Function of Temperature Difference between Pressurant Gas and Liquid.

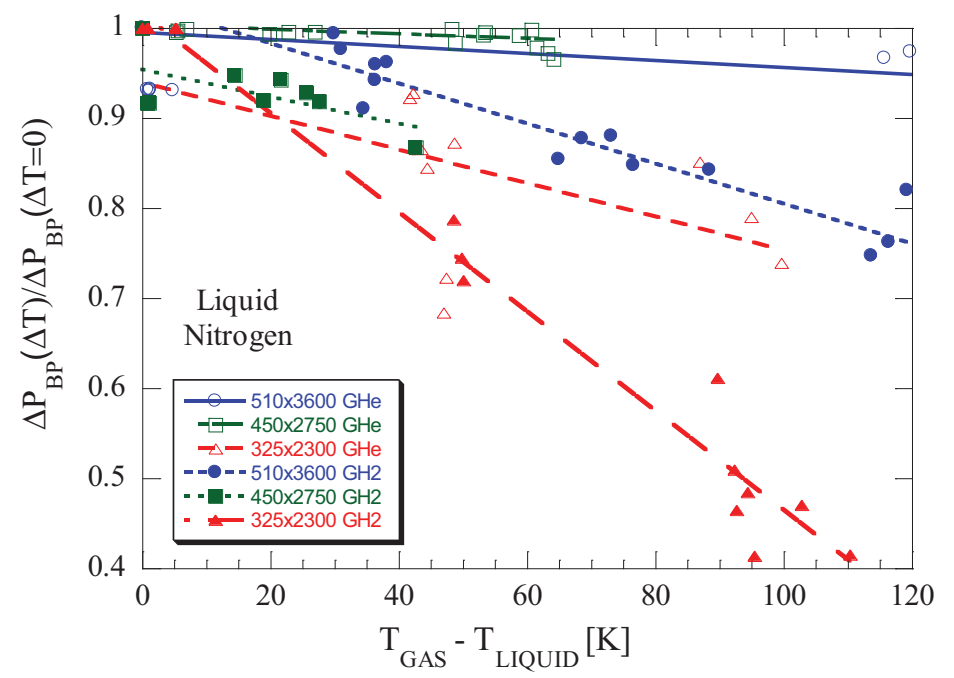

Fig. 13 Normalized Heated Pressurant Gas $\mathrm{LN}_{2}$ Bubble Point Pressure as a Function of the Temperature Difference between Pressurant Gas and Liquid at the LAD Screen. 


\section{Conclusion}

Experimental results here confirm that elevating the pressurant gas temperature above the liquid temperature always acts as a degradation factor on the performance of the LAD. Three fine mesh screen channel LAD s amples were tested in $\mathrm{LH}_{2}$ and $\mathrm{LN}_{2}$ using heated non-condensable $(\mathrm{GHe})$ and condensable $\left(\mathrm{GH}_{2} / \mathrm{LH}_{2}\right.$ or $\left.\mathrm{GN}_{2} / \mathrm{LN}_{2}\right)$ gases for temperature difference between the pressurant and liquid of $0-91 \mathrm{~K}$ and $0-131 \mathrm{~K}$ for $\mathrm{LH}_{2}$ and $\mathrm{LN}_{2}$, respectively. For all three meshes, both liquids, and both pressurization schemes, normalized bubble point pressure ratio decreases linearly with increasing gas temperatures. Degradation in performance is much sharper using condensable gas es versus using non-condensable gases. The reduction in LAD performance scales inversely with the porosity of the screen for both liquids and pressurization schemes, as the finest $510 \times 3600$ mesh exhibited the least amount of degradation, and the coarsest $325 \times 2300$ mesh had the highest reduction in performance. For heated $\mathrm{LH}_{2}$ bubble point tests, the onset of degradation always occurred immediately with warm gas for all three meshes, whereas for heated $\mathrm{LN}_{2}$ tests, the onset of degradation did not occur below a minimum temperature difference between the

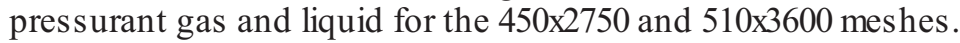

Differences in performance between the three different screens are due to the effect of the screen thickness and porosity on the overall heat transfer across the LAD screen. Differences in performance between pressurants are due to modified heat and mass transport at the screen pore L/Vinterface through evaporation $(\mathrm{GHe})$ and/or condensation $\left(\mathrm{GH}_{2}\right.$ or $\left.\mathrm{GN}_{2}\right)$. Differences in performances between the two liquids have been explained through the differences in superheats required to initiate boiling in the liquid.

Results here have direct impact on future LAD and pressurization system design for low surface tension liquids, especially for future cryogenic hydrogen fueled depots. The bubble point pressure of screen channel liquid acquisition devices represents the upper limit on the total allowable pressure loss, and thus flow rate from the LAD to a trans fer line en route to an engine or receiver depot tank. Higher bubble points are always obtained when the gas used to pressurize the propellant tank, and thus flow liquid through the LAD, is as cold as possible relative to the liquid, with the highest values obtained when the pressurant gas and liquid temperature are approximately equal. However, unless the pressurant gas bottles and propellant tanks are thermally linked, or subsurface pressurization methods are employed, the gas will always be significantly warmer than the cryogenic propellant and some degradation in LAD performance will be expected for all real mission scenarios. This work quantifies this effect.

\section{Acknowledgments}

This work was funded by the Cryogenic Propellant Storage and Transfer Project under the Office of the Chief Technologistat NASA. The authors would like to thank the operations teamand research support staff at CCL-7 for their assistance during planning, design, and testing phases.

\section{Appendix A - Previously Reported Experiments}

There are four ways to experimentally test LAD performance. The easiest and most straightforward method to characterize the limits for a screen channel LAD is to measure the bubble point of a small screen sample. The method using an inverted bubble point (IBP), with liquid on top and vapor or gas on the bottom, is preferable over the non-inverted bubble point (NIBP) method for the following reas ons: It is easier to control liquid head pressure on the submerged LAD screen sample, it is eas ier to deduce breakthrough pressures, and bubbles that break through the screen naturally rise away from the screen during breakthrough. A third method for testing LAD performance involves flowing liquid through a complete LAD channel as sembly until the screen breaks down and vapor is ingested into the channel. Static IBP or NIBP tests are preferred over dynamic inverted outflow (IO) tests because IO test results can vary based on how the tank was pressurized, how the gas impinges on the screen (ex. parallel vs. perpendicular to screen face), and due to nonuniform pressurant gas temperature gradients which may develop during outflow. A fourth method for testing LAD performance is similar to the bubble point testing and involves immersing the entire screen element in liquid, draining the liquid, and pressuring the element with gas unt il bubble breakthrough. This method is used to test start baskets and traps, which are used for holding small amounts of liquid within the tank for engine restart.

A rigorous review of the literature revealed a total of 10 relevant studies of warmpres surant gas effects on LAD performance. LAD performance is affected by the surface tension, and, thus temperature. Therefore to make meaningful comparis ons, his torical results are organized by propellant type (function of saturation temperature), and then by screen type. A brief overview of historical results is presented chronologically.

Castle [26] first attempted to quantify the effect of heated pressurant on screen channel LAD performance. Using a standard NIBP configuration, they reported static bubble point tests conducted in $\mathrm{LN}_{2}$ using $\mathrm{GN}_{2}$ for six different 
screen samples. $\mathrm{GN}_{2}$ was heated electrically and forced downward on the LAD screen using a fan in an attempt to eliminate natural convection in favor of forced convection. For a $\Delta \mathrm{T}=50 \mathrm{~K}$ across the screen, there was no degradation in performance for any screen mesh. Only the 250x600 mesh screen showed a $31 \%$ degradation in performance at a $\Delta \mathrm{T}=250 \mathrm{~K}$.

Burge and Blackmon [7] reported heated gas $\mathrm{LH}_{2}$ bubble points using a similar NIBP configuration as Castle [26] for three different meshes using $\mathrm{GH}_{2}$ as a pressurant. A fan forced hot $\mathrm{GH}_{2}$ down on the screen, but no attempt was made to eliminate natural convection. Results show performance degradation for all of the screens tested, with the finer 250x1370 mesh performing much worse than the coarser 200x600 mesh. The 250 mesh degraded to $30 \%$ of the cold gas breakdown point. Burge and Blackmon [7] also reported premature breakdown for a 200x1400 mesh with $\mathrm{GH}_{2} / \mathrm{LH}_{2}$ of $50 \%$ but did not report the gas temperature at breakdown. Due to the exis tence of both natural and forced convection, the screen likely broke down prematurely for all these tests. In addition, results are complicated by the fact that the liquid may have been subcooled relative to the pressurant gas tempera ture.

Paynter et al. [27] then conducted the first set of IO tests in $\mathrm{LH}_{2}$ us ing both $\mathrm{GHe}$ and $\mathrm{GH}_{2}$. Test conditions were not reported, but Paynter reported no premature breakdown with warm gas under steady continuous outflow conditions, butpremature breakdown for stepped or ramped expulsions. Blackmon [28] later conducted IO tests for a 250x1370 mesh in $\mathrm{LH}_{2}$ using warm GHe and $\mathrm{GH}_{2}$. Results indicate a degradation in LAD performance as low as $75 \%$ at a $\Delta \mathrm{T}=35 \mathrm{~K}$. Building on Paynter's tests, Warren [29] and Warren et al. [30] report IO data using two layers of $325 \times 2300$ screen mesh in $\mathrm{LH}_{2}$ using both warm $\mathrm{GHe}$ and $\mathrm{GH}_{2}$. Neither saw premature LAD breakdown for continuous or stepped expulsion for a $\Delta \mathrm{T}=19-291 \mathrm{~K}$.

Cady [25] reported NIBP test data for a standard $325 \times 2300$ screen, a pleated $325 \times 2300$, a stainless steel(SS) and aluminum (Al) 200x1400 screen, a 720x140, 165x800, and a SS and Al 120x120 screen in $\mathrm{LH}_{2}$ using warm GHe. There is degradation in heated bubble point values for all meshes tested, with the largest reduction in performance for the $200 \times 1400$ screen. On average there was greater than $10 \%$ reduction in bubble point for temperature differences between gas and liquid as high as $\Delta \mathrm{T}=55 \mathrm{~K}$. When compared to other heated gas $325 \times 2300 \mathrm{LAD}$ data, the data follows the general trend. Cady saw no difference between pleated and unpleated screen performance and saw no difference in performance between SS and Alscreens. Examination of the test apparatus however showed that there was a direct view factor between heating source and screen. Therefore results here are complicated by the fact that heat was being conducted into the pressurant gas and also into the screen itself, which may have caused early breakdown. In addition, it is difficult to compare results from this NIBP configuration where only natural convection was present with those from Castle [26] where forced convection is dominate with Burge and Blackmon [7] where forced and natural convection were present.

Wils on and Meserole [31] report the first known heated pressurant gas LAD performance data using the IBP test configuration for a $325 \times 2300$ screen using $\mathrm{GN}_{2}$ in IPA. They reported a reduction in performance of $69 \%$ of the cold gas bubble point at a $\Delta \mathrm{T}=56 \mathrm{~K}$. But this data may also be corrupted due to the presence of a direct view factor between heat source and screen; the screen may have broken down early due to additional radiation heat transfer.

Bennett [32] tes ted the liquid retention capability of a $34 \mathrm{~cm}$ tall 250x1400 start basket with a 200x1400 window in $\mathrm{LH}_{2}$ using bothnon-condensable and autogenous pressurization schemes. Here the basket was submerged in liquid into a dewar, the liquid level lowered below the basket, and warm pressurant gas was introduced until the basket ingested vapor. With GHe pres surant, no degradation in performance was noted, even when the LAD was subjected to $\mathrm{GHe} 70 \mathrm{~K}$ above the liquid temperature. Using $\mathrm{GH}_{2}$ press urant however, results were not repeatable as the start basket broke down at a height of 0,70 , and $90 \%$ of the cold gas height.

The most recent investigation was conducted by Meserole and Jones [24] for a 325×2300 screen in $\mathrm{LH}_{2}$ using both $\mathrm{GHe}$ and $\mathrm{GH}_{2}$ using an IO test configuration and using $\mathrm{GN}_{2}$ in Freon in an IBP configuration. In the IBP case, $\mathrm{GN}_{2}$ was heated inside a cup with a heating element that was blocked from the screen to prevent stray radiation between heat source and screen. Gas was heated en route to the screen, which was submerged in Freon. A $325 \times 2300$ double-Dutch perforated plate, double plate backed $325 \times 2300$, and a pleated screen sandwich $(32 \times \times 2300,25 \times 25$, $325 \times 2300$ ) were tested. The double-Dutch and double plated samples did not improve screen retention, as bubble point pres sure degraded to $57 \%$ and $67 \%$ of the cold gas values, respectively, for $\Delta \mathrm{T}=83 \mathrm{~K}$ and $100 \mathrm{~K}$, res pectively. The ons et of degradation did not occur until the gas temperature had risen $40 \mathrm{~K}$ above that of the liquid. The pleated sandwich also did not improve screen retention over a single $325 \times 2300$ screen, as warmgas bubble point degraded to $75 \%$ at a $\Delta \mathrm{T}=99 \mathrm{~K}$.

Meserole and Jones [24] also tes ted a $325 \times 2300$ perforated plate sample in $\mathrm{LH}_{2}$ in a modified version of the test apparatus used in the Freon tests, in the IO configuration, and also in hold tests where liquid outflow was stopped for a period of time to allow sufficient residence time of the warm gas inside the dewar that held the LAD channel. IO test results used $\mathrm{GHe}$, para- $\mathrm{GH}_{2}$, and normal $\mathrm{GH}_{2}$ as pressurants. The trends are obvious; for $\mathrm{GHe}$, for a $\Delta \mathrm{T}$ as high as $62 \mathrm{~K}$, there was insignificant degradation (less than $5 \%$ reduction in performance). For hold tes ts with warm 
$\mathrm{GHe}$, there was no change in performance. For normal $\mathrm{GH}_{2}$ pressurization, only a $6 \%$ reduction in performance was reported for a $\Delta \mathrm{T}=54 \mathrm{~K}$ during continuous expulsion tests; for stepped expulsion tests, the LAD broke down at a height of $19 \%$ of the cold gas height when the $\mathrm{GH}_{2}$ was only $5 \mathrm{~K}$ above the liquid temperature. For para- $\mathrm{GH}_{2}$ outflow tests, the LAD broke down at a height of $40 \%$ of the cold gas value at a $\Delta \mathrm{T}=26 \mathrm{~K}$; for hold tes ts, the LAD broke down at a height of $19 \%$ of the cold gas height for a $\Delta \mathrm{T}=6 \mathrm{~K}$.

Although trends from Meserole and Jones [24] are fairly obvious, in that GHe performed much better than $\mathrm{GH}_{2}$ for both IBP and IO test configurations, the results are not repeatable and are complicated by the following reas ons. First, the LAD itself was not sized properly. The hydrostatic head pressure inside the LAD when the LAD was completely exposed to gas was never enough to overcome the static bubble point pressure. As a result of the poorly sized LAD, a flow restriction orifice was used on the $\mathrm{LH}_{2}$ inflow to help build up additional pressure differential. LAD breakdown was actually induced through the use of this flow restriction at the bottom of the tank by ramping the ullage pressure while still flowing through the flow restriction. The liquid level always dropped below the bottomof the LAD screen and breakdown only occurred when ramping the ullage pressure. It is unclear what the flow rate was during this pressurization event, and this is an indirect (and not direct) way to break the channel down. Second, warmgas was always injected at a temperature much greater than the actual temperature of the gas at the screen at breakthrough. Without direct measure of the temperature at the screen, it is unclear what the actual gas temperature was at the screen at breakdown. Third, for IO tests, a curved LAD was used, which only serves to complicate interpretation of results due to nonuniform flow-through-screen pressure losses. Fourth, while GHe and para- $\mathrm{H} 2$ tests were fairly repeatable, there is quite a large discrepancy between para- $\mathrm{GH}_{2}$ and normal $\mathrm{GH}_{2}$ results, despite the fact that there is only a $1-2 \%$ increase in surface tension for para over normal hydrogen.

In summary, past inverted outflow tests are not ideal for as sessing the fundamental effect of warmpres surant gas on LAD performance due to complexities in reducing the data, in controlling pressurant gas flow, and in controlling uniformity of the gas temperature. Dynamic IO tests are more flight representative than the simple static screen sample tests because the IO tests simulate 1-g outflow through a LAD channel from a larger propellant tank. However, for IO outflow tests, it is extremely difficult to control the location and direction of pressurization and also the uniformity of the temperature of the warm gas inside the tank relative to the LAD; even small changes in the direction or temperature of the gas can cause noticeable differences in the breakdown height of the channel as is shown in the historical data. The NIBP configuration is also not preferred due to complexities in controlling pressurant gas temperature and controlling gas flow down on the screen (i.e. natural vs. forced convection). Mean while, the IBP configuration is well suited to address this effect provided that careful attempts are made to heat only the gas, and not the screen. Care must also be taken to as sure uniformity of temperature rise and to precisely measure the temperature of the pressurant gas before incidence on the screen. IBP configurations are preferred over IO configurations because it is better to heat the gas, then have the gas incident on the screen rather than warm the ullage space inside a large tank and then allow it to cool as it comes in contact with the LAD. Most discrepancies in previously reported experiments are due to these aforementioned concerns which can be mitigated through the new IBP experimental design presented in the current work.

\section{References}

${ }^{1}$ McLean, C., Mustafi, S., Walls, L., Pitchford, B., Wollen, M., and Schmidt, J., "Simple, Robust Cryogenic Propellant Depot for Near Term Applications" 2011 IEEE Aerospace Conference, Big Sky, MT, March, 2011.

${ }^{2}$ Fester, D.A., Villars, A.J., and Uney, P.E., "Surface Tension Propellant Acquisition System Technology for Space Shuttle Reaction Control Tanks" AIAA Paper 75-1196, AIAA/SAE Propulsion Conference, Anaheim, CA, September, 1975.

${ }^{3}$ Peterson, R. and Uney, P., "Development and Qualification of the Space Shuttle Orbiter Reaction Control System Propellant Tank" AIAA Paper 78-1026, AIAA/SAE Joint Propulsion Conference, Las Vegas, NV, July, 1978.

${ }^{4}$ Schweickert, T.F., "Design of the Aft Propulsion Subsystem for Long Life" JANNAF Propulsion Meeting, New Orleans, May, 1981.

${ }_{5}^{5}$ Anglim, D.D., "Space Shuttle Aft Propulsion Subsystem” AIAA Paper 81-1511. 1981.

${ }^{6}$ Anderson, J.E., "Superfluid Helium Acquisition System Development" Cryogenics Vol. 29, No. 5, 1989, pp. 513 - 516.

${ }^{7}$ Burge, G.W. and Blackmon, J.B., "Study and Design of Cryogenic Propellant Acquisition Systems - Volume II Supporting Experimental Program” NAS8-27685 MDAC Report MDC G5038, 1973.

${ }^{8}$ Burge, G.W., Blackmon, J.B., and Castle, J.N., "Design of Propellant Acquisition Systems for Advanced Cryogenic Space Propulsion Systems" AIAA/SAE Propulsion Conference Las Vegas, NV, November, 1973.

${ }^{9}$ Zimmerli, G. A., Asipauskas, M., and Van Dresar, N. T., "Empirical correlations for the solubility of pressurant gases in cryogenic propellants," Cryogenics, Vol. 50, No. 9, 2010, pp. 556-560.

${ }^{10}$ Stiegemeier, B., Williams, G., Melcher, J.C., and Robinson, J., "Altitude Testing of an Ascent Stage LOX/Methane Main Engine" $5^{\text {th }}$ JANNAF Liquid Propulsion Subcommittee Meeting, May, 2010. 
${ }^{11}$ Hartwig, J.W., and Mann, J.A., “A Predictive Bubble Point Pressure Model for Porous LAD Screens” Journal of Porous Media (in press). 2014.

${ }^{12}$ Hartwig, J.W. and Mann, J.A., "Bubble Point Pressures of Binary Methanol/Water Mixtures” AIChE Journal Vol. 60, No. 2, 2014 , pp. $730-739$.

${ }^{13}$ Hartwig, J.W., Mann, J.A., Darr, S.R., and Chato, D.J., "Parametric Analysis of the Liquid Hydrogen and Nitrogen Bubble Point Pressure for Cryogenic Liquid Acquisition Devices" Cryogenics (accepted for publication) 2014.

${ }^{14}$ Hartwig, J.W., McQuillen, J.B., and Chato, D.J., "Screen Channel LAD Bubble Point Tests in Liquid Hydrogen" International Journal of Hydrogen Energy Vol. 39, No. 1, 2014, pp. 853 - 861.

${ }^{15}$ Jurns, J.M. and McQuillen, J.B., "Liquid Acquisition Device Testing with Sub-cooled Liquid Oxygen" AIAA Paper 2008 4943, Joint Propulsion Conference and Exhibit, Hartford, CT, July, 2008.

${ }^{16}$ Hartwig, J.W., McQuillen, J.B., and Chato, D.J., "Performance Gains of Propellant Management Devices for Liquid Hydrogen Depots" AIAA Paper 2013-0368, Aerospace Sciences Meeting, Grapevine, T X, January, 2013.

${ }^{17}$ Hartwig, J.W. and McQuillen, J., "Analysis of Screen Channel LAD Bubble Point Tests in Liquid Oxygen at Elevated Temperature" AIAA Paper 2011-3775, Thermophysics Conference, Honolulu, HI, June, 2011.

${ }^{18}$ Hartwig, J.W. and McQuillen, J., "Analysis of Screen Channel LAD Bubble Point Tests in Liquid Methane at Elevated Temperature” AIAA Paper 2012-0759, Aerospace Sciences Meeting, Nashville, T N, January, 2012.

${ }^{19}$ Hartwig, J.W. and McQuillen, J., "Screen Channel LAD Bubble Point Tests in Liquid Methane" Journal of Thermophysics and Heat Transfer (accepted for publication). 2014

${ }^{20}$ Hartwig, J.W., McQuillen, J., and Jurns, J., "Screen Channel LAD Bubble Point Tests in Liquid Oxygen" Journal of Thermophysics and Heat Transfer (accepted for publication). 2014.

${ }^{21}$ Hartwig, J.W. "Liquid Acquisition Devices for Advanced In-Space Cryogenic Propulsion Systems" Dissertation, Case Western Reserve University, Cleveland OH, May, 2014.

${ }^{22}$ Hartwig, J.W. and Darr, S.R. "Influential Factors for Liquid Acquisition Device Screen Selection for Cryogenic Propulsion Systems" Applied Thermal Engineering Vol. 66, No. 1-2, 548 - 562. 2014.

${ }^{23} \mathrm{Li}, \mathrm{C}$. and Peterson, G.P., "The Effective Thermal Conductivity of Wire Screen" International Journal of Heat and Mass Transfer Vol. 49, No. 21-22, 2006, pp. 4095 - 4105.

${ }^{24}$ Messerole, J.S. and Jones, O.S.,"Pressurant Effects on Cryogenic Liquid Acquisition Devices" Journal of Spacecraft and Rockets Vol. 30, No. 2, 1993, pp. 236 - 243.

${ }^{25}$ Cady, E.C., "Design and Evaluation of Thermodynamic Vent/Screen Baffle Cryogenic Storage System," NASA-CR134810,1975 .

${ }^{26}$ Castle, J.N., "Heat Transfer Effects on Bubble Point Tests in Liquid Nitrogen” MDC02653, 1972.

${ }^{27}$ Paynter, H.L., "Acquisition/Expulsion System for Earth Orbital Propulsion System Study, Volume II” NASA-CR-134154, 1973.

${ }^{28}$ Blackmon, J.B., "Design, Fabrication, Assembly, and Test of a Liquid Hydrogen Acquisition Subsyst em" NASA-CR120447,1974

${ }^{29}$ Warren, R.P., “Acquisition System Environmental Effects Study” NASA-CR-120768. 1975

${ }^{30}$ Warren, R.P., Butz, J.R., and Maytum, C.D. “Measurements of Capillary System Degradation” AIAA Paper 75-1197.

${ }^{31}$ Wilson, A.C. and Messerole, J.S., "Liquid Hydrogen Acquisition Device Component Fabrication and Testing" D18029345-1. 1986.

${ }^{32}$ Bennett, F.O., "Design and Demonstrate the Performance of Cryogenic Components Representative of Space Vehicles, Start Basket Liquid Acquisition Device Performance Analysis" NASA-CR-179138. 1987. 